\title{
Training and organizational effectiveness: moderating role of knowledge management process
}

\begin{abstract}
Purpose - Training alone is not sufficient to enhance organizational effectiveness to a greater level because not all knowledge obtained from the training is properly transferred and applied to the organization. This study aims to investigate whether efforts invested by Malaysian manufacturers in employee training and knowledge transfer affect organizational effectiveness. Design/methodology/approach - This study adopted a quantitative research design. The questionnaire developed for this study captured the training related to individual/managerial skills, the knowledge management process in place to capture and apply the knowledge obtained through training, and the organizational effectiveness. A closed-ended online survey was sent to 1,000 members of the Federation of Malaysian Manufacturers (FMM) throughout Malaysia and 88 manufacturers responded. The unit of analysis was an organization. Findings - The study found the following: training employees to acquire individual/managerial skills and process skills helps in improving organizational effectiveness; knowledge application and knowledge protection interact with individual/managerial skills training to improve organizational effectiveness; and knowledge acquisition, knowledge application and knowledge protection interact with process skills training to enhance organizational effectiveness. Practical implications - Organizations are urged to devise training modules depending on the needs of individual employees, create an environment that will encourage the trained employees to apply their skills (knowledge), and develop policies to retain these employees. Originality/value - This paper addresses an important and not so well researched issue. It analyzes the interactions between the dimensions of knowledge management practices and type of training in improving the organizational effectiveness of manufacturing firms in Malaysia
\end{abstract}

Keyword: Training; Knowledge management practices; Organizational effectiveness; Manufacturing firms; Malaysia; Knowledge management 